\title{
PENGARUH LAYANAN KONSELING KELOMPOK DENGAN TEKNIK PENGELOLAAN DIRI UNTUK MENGURANGI PERILAKU PELANGGARAN DISIPLIN SEKOLAH DI KELAS VIII SMP NEGERI 14 BENGKULU TENGAH
}

\author{
Nisa Lisnawati, Wasidi, Vira Afriyati \\ Prodi Bimbingan dan Konseling Fakultas Keguruan dan Ilmu Pendidikan \\ Universitas Bengkulu \\ nisalisnawati16@gmail.com,wasidi@unib.ac.id,vira_afriyati@unib.ac.id
}

\begin{abstract}
ABSTRAK
Penelitian ini bertujuan untuk mendeskripsikan pengaruh layanan konseling dengan teknik pengelolaan diri untuk mengurangi perilaku pelanggaran disiplin sekolah di kelas VIII SMP Negeri 14 Bengkulu Tengah. Desain penelitian one group pretest dan posttes design, dengan sampel siswa kelas VIII sebanyak 38 orang siswa, pengambilan sampel menggunakan teknik purposive sampling. Data dianalisis dengan menggunakan uji t. Hasil penelitian menunjukkan bahwa adanya pengaruh yang signifikan antara layanan konseling kelompok terhadap perilaku pelanggaran disiplin, dengan nilai $t=-9,629(\mathrm{p}<0.05)$. Maka dapat disimpulkan bahwa ada pengaruh antaral ayanan konseling kelompok terhadap perilaku pelanggaran disiplin di SMP Negeri 14 Bengkulu Tengah.
\end{abstract}

Kata kunci : layanan konseling kelompok, perilaku pelanggaran disiplin

\section{INFLUENCE OF COUNSELING CONSOLIDE SERVICES WITH SELF- MANAGEMENT TECHNIQUES TO REDUCE BEHAVIOR OF DISCIPLINE SCHOOL CLASS VIII SMP NEGERI 14 BENGKULU TENGAH}

\begin{abstract}
This study aims to describe the influence of counseling services with self-management techniques to reduce the behavior of school discipline violations in class VIII SMP Negeri 14 Bengkulu Tengah. The research design of one group pretest and posttes design, with a sample of students of class VIII of 38 students, sampling using purposive sampling technique. Data were analyzed by using $t$ test. The results showed that there was a significant influence between group counseling services on disciplinary behavior, with $t$ value $=-9,629(p<0.05)$. So it can be concluded that there is influence between group counseling services on disciplinary behavior of discipline in SMP Negeri 14 Bengkulu Tengah.
\end{abstract}

Keywords : group counseling service, discipline breach behavior 


\section{Pendahuluan}

Menurut Robert W. Richey (dalam Bestari, 2012: 8) pendidikan adalah sebuah proses yang lebih luas daripada proses yang berlangsung di dalam sekolah saja, pendidikan merupakan suatu aktivitas sosial yang memungkinkan masyarakat tetap ada dan berkembang. Pendidikan adalah segala pengaruh yang diupayakan sekolah terhadap anak dan remaja yang diserahkan kepadanya agar mempunyai kemampuan yang sempurna dan kesadaran penuh terhadap hubungan-hubungan dan tugas-tugas sosial mereka. Pendidikan pada umumnya bertujuan untuk membentuk manusia yang bermoral dan berilmu.

Pendidikan sekolah bertujuan menghasilkan perubahan-perubahan positif (tingkah laku dan sikap) dalam diri siswa yang sedang berkembang menuju kedewasaannya. Peran sekolah sangat besar pengaruhnya untuk para peserta didik terutama untuk kedisiplinan siswa. Kedisiplinan merupakan suatu usaha untuk memelihara perilaku agar tidak mendorong siswa untuk berperilaku menyimpang sehingga tidak membuat siswa tersebut melakukan hal yang melanggar norma, peraturan dan tata tertib disekolah.

Perilaku menyimpang merupakan perilaku yang tidak disiplin, salah satunya melakukan pelanggaran disiplin sekolah. Pelanggaran disiplin sekolah yang sering dijumpai dan terlihat yaitu, masih terdapat siswa yang terlambat untuk datang kesekolah, tidak masuk tanpa keterangan, sengaja tidak mengikuti kegiatan belajar mengajar disekolah, tidak mengikuti upacara bendera, membolos di waktu jam pelajaran, membawa hp kesekolah, tidak memakai seragam/atribut lengkap, dan melakukan pelanggaran disiplin lainnya (Safitri dan Elisabeth, 2002: 2). Biasanya pihak sekolah menangani kasus pelanggaran disiplin hanya dengan mencatat dalam buku non akademis, memanggil orang-tua, memberi hukuman, memberikan peringatan.

Untuk membuat siswa tidak melakukan pelanggaran disiplin sekolah, konselor bisa memanfaatkan bimbingan dan konseling di sekolah kepada siswa/siswi dengan memberikan salah satu layanan yang ada dalam bimbingan dan konseling yaitu salah satunya konseling kelompok. Menurut Latipun (dalam Masfufah, 2012: 17) konseling kelompok merupakan salah satu bentuk konseling dengan memanfaatkan kelompok untuk membantu, memberi umpan balik dan pengalaman belajar. Pentingnya memberikan konseling kelompok dapat memberikan individu berbagai macam pengalaman yang dapat membantu mereka dalam mengemukakan pendapat dan bersosialisasi dalam lingkungannya. Kegiatan layanan 
konseling kelompok untuk mengurangi perilaku pelanggaran disiplin sekolah dengan menggunakan teknik pengelolaan diri.

Teknik pengelolaan diri dikenal sebagai proses eksekusi (pengambilan keputusan). Pengelolaan diri adalah suatu strategi pengubahan perilaku yang dalam prosesnya konseli mengarahkan perubahan perilaku sendiri dengan teknik teurapetik Cormier \& Cormier (dalam Alamri, 2015: 2).

Dengan demikian maka melalui layanan konseling kelompok dengan teknik pengelolaan diri dapat memberikan perubahan perilaku pelanggaran disiplin yang telah dilakukan dan membuat siswa bisa menjadi perilaku yang baik dan benar, sehingga dapat diterapkan oleh siswa dalam kehidupan sehari-harinya. Tujuan dari penelitian ini adalah untuk mendeskripsikan perilaku pelanggaran disiplin sekolah sebelum dan sesudah pemberian layanan konseling kelompok. serta untuk mendeskripsikan ada tidaknya pengaruh pemberian layanan konseling kelompok terhadap perilaku pelanggaran disiplin.

\section{Metode Penelitian}

Metode yang digunakan dalam penelitian ini adalah metode eksperimen dengan jenis one group pretest-posttest design, yang melakukan dua kali pengukuran. Peneliti dapat mengetahui bagaimana perilaku pelanggaran disiplin sekolah sebelum diberikan layanan konseling kelompok (pre-test). Setelah itu peneliti juga dapat mengetahui bagaimana peningkatan perilaku disiplin sekolah sehingga tidak melakukan pelanggaran disiplin setelah dilakukannya layanan konseling kelompok (post-test). Dapat dilihat seberapa besar pengaruh layanan konseling kelompok yang diberikan terhadap peningkatan perilaku disiplin siswa.

Pengambilan sampel ini menggunakan teknik purposive sampling, sehingga didapatkan 8 peserta didik kelas VIII SMP Negeri 14 Bengkulu Tengah. Rantang waktu penelitian yang dilaksanakan pada tanggal 24 Mei- 08 Juni 2018.

Teknik pengumpulan data yang digunakan yaitu berupa angket perilaku pelanggaran disiplin sekolah. Angket berisi pernyataan yang merujuk pada aspek-aspek yang terdiri dari disiplin waktu, disiplin menegakkan aturan, disiplin beribadah dan disiplin sikap.

Pengujian validitas menggunakan uji validitas isi dengan pengajuan kepada ahli dalam bidang pembuatan butir-butir soal (Exspert judgment), pengajuan kepada ahli bertujuan untuk menghindari kurang tepatnya butir-butir soal.Angka yang menunjukkan besarnya daya beda disebut indeks diskriminasi disingkat $D$. Pada penelitian ini, peneliti menggunakan batas nilai $D>0,20$ jika dibawahnya maka aitem akan dinyatakan gugur. Berdasarkan hasil uji coba 
tersebut dari 45 aitem yang diujicobakan didapatkan 10 aitem yang gugur dan 35 aitem dinyatakan valid. Uji reliabilitas dengan melihat Cronbach' Alpha didapatkan hasil 0,896 yang berarti realibilitas dari angket tersebut sangat tinggi.

Perlakuan yang diberikan dalam penelitian ini adalah layanan konseling kelompok. pemberian layanan konseling kelompok sebanyak 6 kali pertemuan. Pertemuan pertama mencatat perilaku siswa yang akan diperbaiki, pertemuan kedua dan kelima peserta didik menceritakan perubahan yang telah dilakukan dan yang telah diperbaiki, pertemuan keenam mengevaluasi perubahan dari perilaku yang telah diperbaiki. Untuk menguji hipotesis, datadata yang terkumpul akan dianalisis secara statistik melalui uji $t$ dengan menggunakan perhitungan komputerisasi program SPSS.

\section{Hasil dan Pembahasan}

Penentuan klasifikasi skor perilaku disiplin peserta didik mengikuti layanan konseling kelompok yang diukur berdasarkan data hipotetik, dengan skor minimum 92, skor maksimum 173, mean 146,9 dan standar deviasi 18,1. Kategori perilaku disiplin menggunakan 5 kategori. Kategori tersebut adalah sangat tinggi, tinggi, sedang, rendah dan sangat rendah. Adapun distribusinya, yaitu:

Tabel 1

DistribusiFrekuensiPre-testPerilaku Disiplin

\begin{tabular}{c|c|c}
\hline Kategori & Frekuensi & Persentase \\
\hline Sangat Tinggi & 2 & $5,3 \%$ \\
\hline Tinggi & 28 & $73,6 \%$ \\
\hline Sedang & 0 & 0 \\
\hline Rendah & 8 & $21,1 \%$ \\
\hline Sangat Rendah & 0 & 0 \\
\hline Total & 38 & $100 \%$ \\
\hline
\end{tabular}

Melalui tabel 1 dapat dilihat hasil pretest peserta didik didominasi oleh peserta didik yang masuk dalam kategori perilaku disiplin tinggi yakni 28 peserta didik yang masuk dalam kategori tersebut. 
Tabel 2

DistribusiFrekuensiPost-testPerilaku Disiplin

\begin{tabular}{c|c|c}
\hline Kategori & Frekuensi & Persentase \\
\hline Sangat Tinggi & $\mathbf{0}$ & $\mathbf{0}$ \\
\hline Tinggi & $\mathbf{8}$ & $\mathbf{1 0 0 \%}$ \\
\hline Sedang & $\mathbf{0}$ & $\mathbf{0}$ \\
\hline Rendah & $\mathbf{0}$ & $\mathbf{0}$ \\
\hline Sangat Rendah & $\mathbf{0}$ & $\mathbf{0}$ \\
\hline Total & $\mathbf{8}$ & $\mathbf{1 0 0 \%}$ \\
\hline
\end{tabular}

Hasil pre-test seperti pada tabel 2 menunjukkan setelah pemberian layanan konseling kelompok mengenai perilaku disiplin, sudah masuk dalam kategori tinggi. Uji normalitas dalam penelitian ini menggunakan Shapiro Wilk yang merupakan salah satu uji normalitas yang dianjurkan oleh banyak pakar apabila jumlah sampel kecil, yaitu kurang dari atau sama dengan 50 sampel. Kaidah yang digunakan untuk mengetahui normal tidaknya angket adalah jika p>0,05 maka sebaran dikatakan normal. Jika p<0,05 maka sebaran dinyatakan tidak normal. Hasil uji normalitas menunjukkan pretest dengan p sebesar $0,131(\mathrm{p}>0,05)$ yang berarti angket normal dan posttest dengan p sebesar 0,279 ( $\mathrm{p}>0,05)$ yang juga berarti angket normal.

Berdasarkan hasil analisis data diperoleh nilai $\mathrm{t}=-9,629$. Hal ini menunjukkan bahwa layanan konseling kelompok dapat meningkatkan perilaku disiplin . Hasil signifikasi 0,000< 0,05 ini juga menunjukkan kriteria penerimaan atau penolakan bahwa hipotesis Ho ditolak dan Haditerima maka diperoleh hasil bahwa ada pengaruh yang signifikan pada perilaku disiplin antara sebelum diberikan layanan konseling dengan yang setelah diberikan layanan konseling kelompok.

Tabel 3

Hasil Mean Pre-test dan Post-test

\begin{tabular}{c|c}
\hline Pre-test & Post-test \\
\hline 116,6 & 160,8 \\
\hline
\end{tabular}

Dilihat dari mean pre-test dan post-test juga terlihat peningkatan, jika dihitung terjadi peningkatan hingga 44,2 . 
Kedisiplinan penting untuk diterapkan dalam kehidupan sehari-hari, tapi sering menjadi masalah di sekolah karena hampir setiap hari ada saja siswa yang melanggar disiplin. Tarmizi (dalam Fiana, 2013: 28) mengemukakan bahwa "masalah kedisiplinan siswa menjadi sangat berarti bagi kemajuan sekolah" Di sekolah yang tertib akan selalu menciptakan proses pembelajaran yang baik. Sebaliknya, pada sekolah yang tidak tertib kondisinya akan jauh berbeda. Kedisiplinan merupakan sikap atau perilaku yang menggambarkan kepatuhan kepada suatu aturan atau ketentuan.

Menurut Kurnanto (2014: 7) konseling kelompok bersifat memberikan kemudahan dalam pertumbuhan dan perkembangan individu, dalam arti bahwa konseling memberikan dorongan dan motivasi kepada individu untuk membuat perubahan-perubahan dengan memanfaatkan potensi secara maksimal sehingga dapat mewujudkan dirinya. Layanan konseling kelompok adalah proses kegiatan melalui interaksi sosial yang dinamis diantara anggota kelompok dengan membahas masalah-masalah yang sedang dialami oleh setiap anggota kelompok. Sehingga bisa ditemukan cara untuk memecahkan masalah dengan cara yang tepat dan memuaskan. Pada kegiatan konseling kelompok siswa dituntut untuk mampu menyampaikan pendapat, saran ataupun ide demi membantu terentaskannya masalah yang dihadapi dalam anggota kelompok. Melalui konseling kelompok yang intensif dalam upaya pemecahan masalah untuk membuat siswa sadar akan kesalahannya sehingga dapat mengurangi pelanggaran disiplin di sekolah dan bisa melakukan kegiatan belajar mengajar dengan baik tanpa ketinggalan mata pelajaran. Dalam mengurangi pelanggaran disiplin sekolah akan menggunakan teknik pengelolaan diri.

Menurut Sukadji (dalam Komalasari, 2014: 180) pengelolaan diriadalah prosedur di mana individu mengatur perilakunya sendiri. Pada teknik ini individu terlibat pada beberapa atau keseluruhan komponen dasar yaitu, menentukan perilaku sasaran, memonitor perilaku tersebut, memilih prosedur yang akan diterapkan, melaksanakan prosedur tersebut. Anggapan dasar pengelolaan diri merupakan teknik kognitif behavioral bahwa setiap manusia memiliki kecendrungan- kecendrungan positif maupun negatif. Setiap perilaku manusia merupakan hasil dari proses belajar (pengalaman) dalam merespon berbagai stimulus dari lingkungannya. Asumsi yang dipakai dalam penelitian ini adalah konseling kelompok dengan teknik pengelolaan diri. Diharapkan dapat dijadikan wahana pemahaman nilai-nilai positif bagi siswa, khususnya perilaku yang negatif menjadi perilaku yang positif. 
Pertemuan pertama, Anggota kelompok menceritakan satu-persatu semua pelanggaran disiplin yang pernah dilakukan oleh peserta didik beserta hukuman yang sudah diberikan dari sekolah atas pelanggaran yang sudah dilakukan, setelah anggota kelompok menceritakan semua pelanggarannya, anggota kelompok diminta untuk mencatat perilaku pelanggaran disiplin sekolah. Perubahan perilaku yang telah dicatat oleh peserta didik akan dilihat pada pertemuan selanjutnya, kemudian peserta didik memberikan hadiah untuk dirinya sendirijika berhasil untuk memperbaiki perilaku pelanggaran disiplin yang telah dilakukan, sehingga menjadi siswa yang disiplin yang melakukan perilaku yang positif dan memberikan hukuman jika tidak berhasil untuk memperbaiki perilaku pelanggaran disiplin sekolah.

Pertemuan kedua dan kelima, peserta didik menceritakan perilaku yang telah diperbaiki, serta pengaruh dari teman-teman selama melakukan perubahan. Peserta didik menceritakan bahwa selama melakukan perubahan perilaku banyak sekali pengaruh dari teman-teman yang mengajak untuk melakukan pelanggaran, tetapi peserta didik tidak ingin mengikuti dan terpengaruh dari ajakan teman-temannya.Peserta didik berusaha untuk memperbaiki perilakunya, sehingga peserta didik berhasil untuk tidak terpengaruh. Peserta didik yang sudah berhasil melakukan perubahan perilakunya dan peserta didik memberikan hadiah untuk dirinya sendiri, sehingga merasa bangga dengan perubahan perilaku yang kemarin negatif dan sering mendapatkan sangsi dari sekolah menjadi perilaku yang positif, yaitu perilaku yang disiplin.

Pertemuan keenam, mengevaluasi secara keseluruhan dari peserta didik yang mengikuti konseling kelompok. Perubahan-perubahan perilaku yang diceritakan selama konseling kedua sampai konseling kelima, yaitu:tidak berpura-pura sakit saat upacara, tidak merusak fasilitas sekolah, tidak menunda tugas lagi, tidak membolos, tidak merokok di lingkungan sekolah, tidak merusak fasilitas sekolah, tidak datang terlambat, piket dengan tanggung jawab, membuang sampah pada tempatnya, mengirim surat keterangan saat tidak hadir, tidak mengeluarkan baju dan tidak membawa Hp lagi. Peserta didik benar-benar ingin menjadi perilaku yang lebih baik lagi sehingga peserta didik merasa bangga akan perubahan secara keseluruhan yang telah dilakukan selama konseling ini karenapeserta didik mendapatkan dampak positif.

Berdasarkan hasil penelitian dapat dilihat perubahan berupa peningkatan pada perilaku disiplin peserta didik kelas VIII SMP Negeri 14 Bengkulu Tengah setelah diberikan layanan konseling kelompok. 


\section{Kesimpulan}

Berdasarkan hasil penelitian yang telah dilakukan di SMP Negeri 14 Bengkulu Tengah, dapat disimpulkan bahwa perilaku disiplin sekolah sebelum diberikan layanan konseling kelompok masuk dalam kategori perilaku tinggi yakni sebanyak 28 peserta didik dan 8 yang termasuk dalam kategori rendah. Setelah 8 peserta didik diberikan layanan konseling kelompok sudak masuk dalam kategori tinggi. Berdasarkan hasil analisis data dapat disimpulkan bahwa layanan konseling kelompok berpengaruh positif terhadap perilaku pelanggaran disiplin sekolah kelas VIII di SMP Negeri 14 Bengkulu Tengah, dikarenakan nilai signifikansi yang didapat $0,000(<0,05)$.

Diharapkan kedepannya Bagi peserta didik, dengan diberikannya pengetahuan, pemahaman, sertamengenaiperilaku disiplin sekolah, diharapakandapatselalu diterapkan sehingga membantupesertadidikdalam mengurangi perilaku pelanggaran disiplin.Bagi guru pembimbing, disarankan untuk meningkatkan kegiatan pemberian layanan konseling kelompok dengan berbagai teknik khususnya teknik pengelolaan diri agar dapat membantu mengentaskan masalah yang berkaitan dengan masalah pribadi siswa. Bagi peneliti selanjutnya, yang ingin melakukan penelitian lebih lanjut disarankan hasil penelitian ini dapat dijadikan sebagai bahan acuan untuk mengembangkan penelitian lainnya yang berhubungan dengan variabel yang terkait dalam penelitian ini.

\section{Daftar Pustaka}

Amin, S.M. (2016). Bimbingan dan Konseling Islam. Jakarta: Amzah.

Desmita. (2010).Psikologi Perkembangan Peserta Didik.Bandung:Remaja Rosdakarya.

Hikmawati, F. (2014). Bimbingan dan Konseling. Jakarta: RajaGrafindo Persada.

Hurlock, B. Elizabeth. (1980). Perkembangan Anak. Jakarta: Erlangga.

Komalasari, G,Wahyuni, E, \& Karsih. (2014). Teori dan Teknik Konseling. Jakarta Barat: Indeks.

Kurnanto, Edi. M. (2014). Konseling Kelompok. Bandung: Alfabeta.

Redja,M (2010). Pengantar pendidikan. Jakarta: Raja Grafindo Persada.

Prayitno. (2004). Layanan Bimbingan Kelompok Konseling kelompok. Padang: Fkip.

Siregar, S. (2014). Statistik Parametrik Untuk Penelitian Kuantitatif: Dilengkapi dengan Perhitungan Manual dan Aplikasi SPSS Versi 17. Jakarta: Bumi Aksara.

Tu'u, Tulus. (2004). Peran Disiplin pada Perilaku dan Prestasi Siswa. Jakarta: Grasindo. 